\title{
'Using an experimental online digital collection with interactive features to investigate attitudes towards Archives 2.0'
}

\author{
by
}

\section{George Reid Perkins}

Submitted to the School of Information Management,

Victoria University of Wellington

in partial fulfilment of the requirements for the degree of Master of Information Studies 


\section{$\underline{\text { Abstract }}$}

Research Problem: The concept of Archives 2.0 is currently generating much interest within academic and professional discourse in the cultural heritage sector. As yet, however, little research has been done in New Zealand on what potential users and implementers of Archives 2.0 perceive as being the advantages or disadvantages with this idea.

Methodology: This study used a two stage approach. In the first stage an experimental prototype of an Archives 2.0 website was constructed using local cultural heritage resources. This was intended to served as a reference point for discussions about the practical possibility and value of sites of this kind. In the second stage nine qualitative semi-structured interviews were conducted with practitioners and others having a professional interest in cultural heritage collections. They were asked about their perceptions of the practices associated with Archives 2.0 and the current situation in New Zealand

Results: This study found considerable interest in the possibilities represented by Archives 2.0. However, there was also concern about the extra burden on staff resources it was seen to entail. Given this it was generally felt that major projects of this kind would not be feasible within the current economic climate

Implications: This study suggests that the Archives 2.0 concept does have potential for development within the New Zealand cultural heritage sector. However ways will have to be found around concerns over resource constraints before further progress is made. 


\section{Purpose of Research Project}

\subsection{Research Problem}

'Archives 2.0' refers to recent moves by some archival repositories to supplement their online digital collections with Web 2.0 interactive tools. These challenge the traditional understanding and experience of archives by enabling users to have input into the arrangement, description, and display of historical resources. Accordingly, Archives 2.0 has been heralded by many archival theorists and practitioners as evidence of a paradigm shift within the profession. Adherents regard it not just as a suite of tools but as an attitude which, by embracing a postmodern ethos of pluralism, participation, and openness, devises new ways to increase and render more democratic the use of archives (Ketelaar 2008; Palmer 2009). Archives 2.0 is also presented as something that institutions need to adopt if they are to remain relevant, and meet the changing expectations of both users and funding bodies (Daines and Nimer 2009).

As an emergent form of archival practice that is generating considerable interest, Archives 2.0 represents a fruitful area for further research. Its comparative newness means there are relatively few studies covering this topic. In addition, while major (and sometimes controversial) claims are made on its behalf, the nature and extent of Archives 2.0's actual impact remains vague, and is yet to be rigorously tested.

\subsection{Research Questions and Objectives}

This study was constructed around the following research questions:

- To what extent do archival practitioners and users see value in developing Archives 2.0 websites? And what do they perceive as the main advantages or impediments to this mode of making New Zealand cultural heritage collections available online?

This approach is predicated on the understanding that there are currently few online collections in this country with Archives 2.0 functionality, making it necessary to investigate potential rather than present use. However, it was also part of the research brief to test assumptions about current levels of activity, with the aim of providing a more informed picture of existing practice in this field.

As originally conceived, the project was intended to be more focused on the perspectives of potential Archives 2.0 users among the wider populace. This is because studies undertaken so far have tended to look at the views of 
professional archivists themselves, indicating a research gap. In practice, however, the task of finding users who were willing to participate, and who were not themselves information professionals, proved too difficult to achieve within the given time constraints. As a consequence, the project became oriented towards practitioners' perceptions. The objective was to acquire data that could be used to provide better insight into what practitioners see as the most effective aspects of Archives 2.0 tools, and the best ways of implementing them. These findings were also used to test the claims and assumptions made about these applications in the professional and academic literature.

\section{Literature Review}

A necessary precursor to Archives 2.0 was the emergence of Web 2.0 and the technological possibilities it represents. First coined in 2004 by the tech publisher Tim O'Reilly, the term 'Web 2.0' was used to identify new developments in the Internet that were seen as transforming it into something qualitatively different in character from before (O'Reilly 2005). In its initial stage, the Web had operated within a traditional one-way broadcast model, in which producers provided static content to passive consumers. Web 2.0, on the other hand, made use of interactive tools that allowed users greater scope for participating and collaborating in, as well as customizing, the creation of dynamic content. As a result, the traditional boundaries between information producers and consumers became blurred. While there is still considerable debate over what precisely 'Web 2.0' refers to and just how significant a development it is, the concept has become increasingly widely used and applied in a variety of fields, many of them, such as libraries and museums, cognate with archival activities (Miller 2005; Notess 2006; Madden \& Fox 2006; Umbach 2006).

One of the defining components of Archives 2.0 is the use of interactive software by archival institutions to deliver online digital collections. At the same time, an important theme that emerges from a review of the literature is the extent to which, for advocates of Archives 2.0, technology is only half the story. Just as important, is a particular stance towards archival practice that breaks with the traditionally inward-looking, materials-centered, custodial approach exemplified by classical theorists such as Sir Hilary Jenkinson (Jenkinson 1980). In its place, advocates of Archives 2.0 promote a more open, collaborative, and user-centric attitude towards their work. In this regard, the emergence of the underlying philosophies associated with Archives 2.0 predates the creation of the actual technologies on which it is based by at least two decades.

One important strand of thought can be traced back to the work of Elsie Freeman in the 1980s (Freeman 1984). Reflecting her background in public 
programming - a neglected area of archival practice at that time- Freeman's 'client-centered' approach held that archivists needed to break with their traditional custodial mind-set and become more zealous about promoting awareness of, and access to, the records in their care. As a key to this approach archivists needed to find out who their users were and what they wanted, and re-orient their activities to better cater to these needs. Following Freeman, many other archival thinkers called for attention to be paid to public relations and the development of more 'user-friendly' forms of access (Jimerson 1989; Ericson 1990/1991; Grabowski 1992; Malbin 1997). Like Freeman, they drew heavily on the work of management theorists, particularly the marketing and 'quality gurus' prominent at the time. Accordingly, they tended to emphasize an image of archives as a 'business', in 'competition' with other information providers for 'customers', whose 'survival' depended on learning how to more efficiently satisfy their users' needs (and, in the process, to impress 'resource allocators'). For this they were criticized by Terry Cook, who argued that they sought to move archives in the direction of a 'trendy consumerism' (Cook 1990/1991, p.131). Cook also warned that giving primacy to user needs could undermine the materials-based authority control necessary for securing a record's status as evidence (Cook 1990/1991).

An example of the continuity between the views espoused by Freeman et al. and more recent work on archives and Web 2.0, is Daines and Nimer (2009). Like the majority of literature in this field, this is not a methodologically formal research project so much as a piece of advocacy linked to a survey of current developments. Appropriately enough, the latter takes the form of a wiki, run in conjunction with the Society of American Archivists (SAA), to which archives are invited to contribute case studies reporting on their own experiments with interactive applications such as wikis, blogs, and mashups. In a similar manner to Freeman et al., Daines and Nimer's accompanying essay has a customer service orientation that draws on marketing theory to justify the greater use of these tools by archives. Their paradigm is 'wikinomics': the idea that Web 2.0 has created a new business environment based around mass collaboration and the blurring of the line between producers and consumers. Companies must adapt to the expectations created by this new environment or perish (Tapscott \& Williams 2007). Daines and Nimer argue that commercial precepts apply equally to non-profit organisations like archives, which, in order to remain relevant, should abandon their 'anachronistic parochialism' and, via Web 2.0, open up their data to patrons. The right attitudes are as important as the right technologies, with the four key principles identified as openness, peering, sharing, and acting globally. Collaboration with users and with other archivists is a means of promoting the use of collections and securing the support of funding bodies (Daines \& Nimer 2009).

A different, if connected, strand of thinking in the literature on Archives 2.0 is the influence of postmodern ideas. Rather than emphasizing the 'business case' for adopting Web 2.0, writers in this vein point to its value in advancing a 
political-ethical imperative of 'democratizing' archives. This position draws on earlier postmodern-influenced critiques of a positivist Archival Science criticized for adhering to presumptions of objectivity and a monolithic notion of 'Truth'. These, it was argued, merely masked the degree to which archives have been organized to serve the interests and perspectives of dominant groups. According to postmodernist-aligned accounts, repositories should be reorganized to better reflect and serve the pluralistic character of society as a whole (Brothman 2001; Cook 2000; Harris 1997; Light and Hyry 2002; Nesmith 2002). Archives should recognize 'the diversity, ambiguity, and multiple identities of records creators, information systems, and archive users' (Cook 2001, p.15), and find 'new ways to open up archival description ... to create holes that allow in the voice of our users' (Duff \& Harris, 2002, p.279).

Postmodern archivists were quick to recognize that the dispersed and fluid character of digital technology held important implications for 'the nature of the record, the expectations for access, and the notions of archival control' (Blouin 101, p.103). Eric Ketelaar, in particular, promoted the notion of digital technology as not just a technical augmentation of archival practice, but 'a techno-cultural challenge to connect archives with people' (Ketelaar 2003, p.8), and he welcomed the emergence of Web 2.0 as a substantiation of his belief in the creation of 'People's Archives'. In doing so, he appears to have been one of the first to employ the term 'Archives 2.0':

I propose that we use Web 2.0 features to turn our archives into Archives 2.0, stimulating people to upload their stories, their documents, to the archival server, not only forming relationships between private and public documents, but also establishing communities of records. A community of records may be imagined as the aggregate of records in all forms generated by multiple layers of actions and interactions between and among people and institutions in the community. (Ketelaar 2008, p.17)

Max Evans grounds a slightly different notion of an 'Archives of the People' in deployment of Web 2.0 technology (Evans 2007). His argument draws on legal theorist Yochai Benkler's concept of 'commons-based peer-production' (Benkler \& Nissenbaum 2006). According to Evans, by making minimal metadata about records available online, archivists can, with the help of open source software, crowdsourcing techniques, and folksonomies, use volunteer labour to render these documents more accessible and searchable in accordance with demand (Evans 2007, p.395).

Themes of 'democratizing' access to archives and generating greater user-input into their structure and content, are also prominent in blogs with an Archives 2.0 focus, such as ArchivesNext and Archives Hub Blog (Theimer 2011; Palmer, Stevenson, et al. 2011). Social media tools in their own right, these blogs are an important forum for professional discussion of the latest developments in 
archival use of Web 2.0 applications. Conference presentations are another crucial avenue for this discourse. For example, two papers originally presented at Archives 2.0: Shifting Dialogues Between Users and Archivists, a conference held in Manchester in 2009, offer insights into current attitudes and activities among sectors of the profession promoting greater use of Web 2.0. Palmer (2009) notes the increasing consensus that Archives 2.0 involves 'more a shift in mindset' than a deployment of technology, embracing 'a philosophy that privileges the user and promotes an ethos of sharing, collaboration, and openness', and she acknowledges the direct conflict between this stance and 'some of the most fundamental tenets surrounding 'archival authority' as a possible source of future tensions within the profession (Palmer 2009). (The title of Palmer's paper, 'If We Build It, Will They Come?' also gestures to an underlying anxiety amongst Archives 2.0 advocates about the actual extent of demand among users for these applications.) Flinn (2009) champions the idea that Archives 2.0 involves a culture shift within the profession towards 'democratization, a de-centering of authority and perspective, a refiguring of thinking and practice, and a thorough-going participatory ethos' (Flinn 2009). He focuses mainly on the potential of grassroots 'community archives' to use Web 2.0 to generate their own cultural heritage content. While generally sanguine about institutional use of Archives 2.0, he also echoes Palmer's caution about the lack of firm evidence, to date, about its effectiveness.

As these remarks indicate, the relative lack of empirically rigorous research on uptake and use is a notable feature of the current literature on Archives 2.0. With the exception of a handful of studies specifically concerned with Web 2.0 tools (discussed below), most of the relevant methodologically formal social science research is more general, covering online digital collections as a whole. Schaffner (2009), for example, is a very useful and comprehensive report for OCLC that synthesizes insights from thirty years' worth of archives user studies, with an emphasis on what has been learnt about online finding aids. Her analysis indicates that strong evidence already exists about the kind of descriptive metadata required to better match users' information-seeking behavior. She identifies a well-documented gap between an archival focus 'on what collections are made up of (Ofness)' and the search needs of users who 'prefer to learn what collections are about (Aboutness)' (Schaffner 2009, p.6). The development of user-friendly metadata becomes particularly pressing within a virtual environment where archivists are no longer physically present to mediate searches. The report concludes by arguing for moving beyond outdated dictates of archival science, and fundamentally rethinking online descriptive practices.

Dorner, Liew, and Yeo (2007) is a user study with a New Zealand context aimed at gathering empirical information on the perceived needs of those who utilise digital cultural heritage collections. It uses self-administered questionaires, semi-structured interviews, and a focus group to obtain rich qualitative data on what users of these resources saw as the major benefits and drawbacks of 
online access to primary source material. Concerns identified include inadequate metadata for findability, worries about the authenticity of documents, and the loss of contextual information through the digitization process. On the positive side, one of the most valued features is convenience of access - with integrated sites that provided a single gateway to a range of material dispersed across different institutions, being particularly appreciated. The 'added value' offered by digital technology's ability to recontextualize items in multiple ways (such as through hyper-links, alternative interfaces, or mashups), is also valued This capacity to 'encourage engagement by different users on different levels and from varying points of view' is seen as the principle advantage of the online format over physical archives (Dorner, Liew \& Yeo 2007, p.174). Another kind of user study, which emphasizes the user testing of interface design, is provided by Stevenson (2008). This study employs semi-structured interview sessions with participants seated in front of a monitor displaying pages from the archival website being evaluated. Openended questions are used to gain insight into users' unassisted understanding of the information on display, and their reaction to the layout, design, and terminology used. Findings indicate poor comprehension of many standard archival terms (such as 'access points' or 'item level'), a desire for serendipitous browsing, and a preference for self-learning through exploring the site rather than reading instructions (Stevenson 2008).

From the point of view of implementation, Normore (2003) is a substantive investigation into the reasons and procedures behind the establishment of online digitized special collections. The two-phase study employs a contextual design methodology to conduct unstructured interviews in situ with institutions that have chosen to make their collections digitally available online. It then performs a qualitative content analysis of the sites themselves. The main findings are practitioners' enthusiasm for these new practices, the importance of developing better metadata to facilitate independent use, and the fear that time and energy spent maintaining these sites may distract from traditional archival tasks. Liew (2006) is a questionnaire-based study, conducted with cultural heritage institutions in a number of countries, that looks at the reasons for setting up online digital exhibitions of archival material. Unsurprisingly perhaps, it finds that online exhibitions are favoured over onsite ones because of their ability to reach a broader audience and be sustained for a greater length of time. Less obviously, it also notes that the opportunity they provide for building collaborative partnerships with other institutions is also highly valued (Liew 2006).

Two recent studies specifically examine the uptake of Web 2.0 tools by archives. Nogueira (2010) is presented as a systematic international survey of archives that have chosen to establish a presence on social media sites Facebook, Flickr, and YouTube. While its methodology is not especially rigorous, it finds that archives are increasingly using these commercial applications to a generally positive reception. According to the study, the main 
advantages of a social media presence are its ability to increase awareness of a collection, diversify its user base, improve links with other institutions, and provide a means for acquiring more information about individual items. However, the study also notes data security issues in relation to the use of third-party websites, and a level of resistance amongst archivists to the appropriateness of such tools (Nogueira 2010). Samouelian (2009) is a much more substantial and methodologically formal investigation of archives implementing Web 2.0 features on their own websites. The first phase of the study involved a quantitative content analysis of university-affiliated archival websites. This found 45 percent of those hosting a digital collection had at least one Web 2.0 feature, suggesting a growing interest in using these tools. The second phase of the study involved structured interviews with the staff responsible for installing and maintaining these applications. While the sample is too small to be statistically meaningful, the study found that the archivists reported few problems, while their overwhelming perception was that the Web 2.0 tools were extremely popular with users. Respondents also cited as a major advantage that using the tools earned them recognition from their professional peers for being forward-thinking (Samouelian 2009).

An earlier study of the adoption of Archives 2.0 practices by online digital collections was conducted in 2006 by Elizabeth Yakel, one of the most significant researchers in this field. Her content analysis found very little use at that time of social navigation features on archival websites, although there were promising signs of experimentation with 'tagging' (Yakel 2006). Yakel critiqued this lack of uptake of social media tools as indicating a prevailing reluctance by archives to re-conceptualize the traditional relationship between archivists and researchers. She argued that users in a virtual environment must be ceded a more active role in accessing materials, as customary face-to-face modes of mediation no longer applied. To further this goal Yakel pioneered the use of a website incorporating Web 2.0 features as an experimental prototype. As head of the Next Generation Finding Aids research project, she established the well-known Polar Bear Expedition Digital Collections, with the goal of 'reimagining traditional finding aid structure and functionality' in a collaborative virtual environment (Yakel, Shaw \& Reynolds, 2007). Tools used to foster social navigation on the site included bookmarking, user recommender systems, and searchable comments fields. A discussion-oriented commenting system rather than a wiki was employed to preserve the archival 'voice' while still allowing interactivity. An enhanced form of encoded archival description (EAD) was also used to make it possible to browse a variety of access points rather than the standard ones of title and/or creator. The overall aim was to 'create a collaborative and participatory archival and research experience' that would 'fully utilize the electronic environment to display and connect users with archival content' (Yakel, Shaw \& Reynolds, 2007).

A comprehensive evaluative study of the project's first six months was guided by the research question 'Can social navigation features be used to facilitate 
the accessibility of archival materials?' (Krause \& Yakel 2007, p.287). This multi-methodological approach to analyzing use of the site used Web analytics, an online survey, and a content analysis of posted comments. Findings were somewhat mixed. For example, while the small sample of online survey respondents indicated that they appreciated the bookmarks feature, web analytics revealed that it was not much used. The user recommender system was also ambivalently received, although the researchers felt this might be partly due to the site not having attained sufficient critical mass to work properly (Krause \& Yakel 2007, p.300). The comments feature, however, proved popular, as did the facility to browse by subjects. While the researchers were disappointed by the limited use of some of the interactive features, they felt overall that the findings provided 'a glimpse of the future' (Krause \& Yakel 2007, p.312), by vindicating the idea that Web 2.0 tools could be used to render archival materials more accessible.

Following Yakel, others have sought to develop Archives 2.0 websites that double as research projects analyzing the efficacy of such tools. For example, the Samaritan Digital Archives Project began as an effort to digitize and make available online a collection of rare Samaritan texts (Ridolfo, Hart-Davidson, \& McLeod, 2010). It gravitated towards being an experimental Archives 2.0 project when it became apparent that the organizers needed to balance the differing perspectives of the site's two major stakeholders - the Samaritan community, and scholars of Samaritan and Biblical writings. The use of Web 2.0 tools such as image tagging and social networking, provided a means of accommodating this plurality of values and purposes. However, Ridolfo et al emphasise their belief that the Archives 2.0 aspects of the project lay more in the consultative fieldwork required to ensure that the access and representational needs of each stakeholder community was satisfied in the user interface design. They conclude that the promise of Archives 2.0 lies in deploying outreach methodologies to identify ways of allowing multiple stakeholder communities to use archival materials in modes most appropriate to them, while also exposing them to alternative possibilities. Shilton and Srinivasan (2007) followed a similar iterative consultative process in their project to establish a digital archive for the South Asian diasporic community in Los Angeles. Taking an approach grounded in the critique of traditional arrangement and description practices as unrepresentative of marginalized communities, they championed a model of 'participatory appraisal'. This entails a structured series of meetings with community members to assist them to develop their own ontology for identifying, organizing, and describing records on their Web site. By facilitating 'participatory definitions of provenance and ordering' Shilton and Srinivasan challenge traditional archival concepts of control (Shilton and Srinivasan 2007, p.101).

An even more radical position is taken by the Finnish archivist Isto Huvila, who advocates a concept of 'the participatory archive' (Huvila 2008).

Acknowledging important continuities between his work and that of Yakel et al. 
as well as Shilton and Srinivasan, Huvila critiques the former for retaining for the archivist the ultimate authority to organize and describe, and the latter for seeking a consensual 'community ontology' that restricts user participation to the appraisal phase. Such approaches, he argues, 'focus on creating participation around instead of within an archive' (Huvila 2008, p.30). In contrast, Huvila's action research project uses an iterative process of consultation with users to develop an Archives 2.0 website. This makes use of decentralized curation (whereby responsibility for a collection is entirely shared by both users and archivists) and a radical user orientation (in which the findability of resources is prioritized over traditional archival procedures). Technologically, the system rests on a semantic wiki, which maintains a set of minimal requirements that enable crowdsourcing to serve as the fundamental means for organizing and describing content.

Given the controversial character of projects like this, it seems surprising that there is little published work critical of Archives 2.0. That there is opposition within the profession to this approach is often alluded to by Archives 2.0 advocates themselves. Flinn, for examples, reports that a research project he undertook to enable users to contribute to archival descriptions, was scathingly denounced by a 'traditional' colleague as "a frontal attack on professionalism, standards, and scholarship" (Flinn 2010)'. To date, however, published critiques of Archives 2.0 tend to take the form of cautions expressed from a position of general sympathy with Archives 2.0's ideals. Kennedy (2009), for instance, applauds the democratizing potential of this approach but considers it inappropriate for his own work as an online publisher of historic diplomatic documents. According to Kennedy, the politically sensitive character of such records requires that 'a completely secure barrier' be put in place between users and documents to prevent manipulation and abusive comments (Kennedy 2009). He also voices concerns that maintaining technologies of this kind may drain resources from an archivist's primary tasks.

A review of the Archives 2.0-related literature suggests that while many claims have been made in favour of these tools and practices, there is a lack of empirically rigorous research on its uptake and use. Its advocates contend that Archives 2.0 is as much about attitude as technology, endorsing an approach that is open, collaborative, user-centric and broad in outlook. The rethinking of theory and practice includes the development of more accessible and searchable descriptive metadata to provide multiple access points, and to enable browsing and social navigation. Archives 2.0 can also add value to the presentation of resources by enabling them to be approached and contextualized in a variety of ways, while also linking them to other material and points-of-view. Similarly, the opening up archives to user contributions is a way of adding information to items and generating content; including the use of crowdsourcing techniques to prioritize and perform archival tasks. Archives 2.0 also aims to encourage greater collaboration between archival repositories and increased integration of their resources. 
Less positively, there remains an expectation of resistance from more traditional sectors of the profession, with the major concerns being whether the actual extent of user demand justifies implementation, whether time and energy expended on maintaining these sites might distract from other vital tasks, and whether an Archives 2.0 approach might undermine authority control in such a way as to diminish the record's status as evidence.

\section{Methodology and Conduct of Research Project}

\subsection{Methodological Framework.}

This research project was undertaken within a qualitative methodological framework. A qualitative method was chosen as best suited to the subject matter, partly because the target research group (effectively, all potential users or implementers of Archives 2.0 websites) is too amorphous to be confined within a sampling frame meaningful enough for quantitative analysis. The perspectives-based approach of qualitative methods also fitted better with the project's goals of obtaining rich, nuanced data that reflects the personal experience of those who might wish to use Archives 2.0 websites.

The project involved a two-stage approach. The first stage entailed digitizing items from a local archival repository. These digital resources were the basis for constructing a working prototype Archives 2.0 online collection, which was used as an experimental illustration of the sorts of features found on websites of this kind. This step was dictated in part by the lack of actual New Zealand examples of Archives 2.0 to serve as a reference point for discussion. It draws to some extent on the way other investigators in this field have also made use of experimental websites as the basis for their research (Huvila 2008; Ridolfo 2010; Yakel et al. 2007).

In the second phase, a series of qualitative research interviews were conducted. Participants were selected on the basis of their professional interest in cultural heritage collections. Sampling was done using convenienceand snowballing-techniques (ie, following up recommendations from others with knowledge in the field). Interviews were conducted face-to-face, recorded, and subsequently transcribed for analysis. Interviews were flexible, and semi-structured in nature. There was a general list of topics but no fixed questions, and interviewees were encouraged to speak about the subjects that most interested them. The intent was to capture as accurately as possible the interviewees own framing and understanding of the issues. 


\subsection{First Stage: Experimental Ex Libris Website.}

The archival content used for the project's experimental website comes from ex libris collections held at the J. C. Beaglehole Room, Victoria University of Wellington Library. Bookplates proved a suitable choice of subject matter for several reasons. As single discrete images with appealing graphic content, they lend themselves well to the online display and flexible arrangements characteristic of Archives 2.0. Given that bookplates, as physical objects, are generally attached to other objects held in separate collections, they also demonstrate the advantages of digital media for assembling virtual collections. As book-related artefacts, ex libris also proved suitable for research within the field of Information Studies, where there is considerable familiarity with and interest in them. Altogether, 157 bookplates were digitized over a four week period. Substantial research was then undertaken to provide as much detailed metadata as possible.

The website for this study was constructed using Omeka, an open source web publishing platform designed for cultural heritage institutions by the Center for History and New Media at George Mason University. The Omeka platform is free, Web 2.0 functional, and intended for easy use by those without technical know-how. As such, it exemplifies the desire to reduce financial and technological barriers to online collections that is consistent with the democratizing spirit of Archives 2.0. Named 'Ex Libris: an Archives 2.0 bookplates collection,' the Omeka website constructed for the project comprised four separate collections of items tagged to enable their reassembly in various ways. Browsing was also facilitated by a tag cloud and a Google Maps mash-up, displaying items by geo-location. There was a 'Comments' field attached to each item page for users to discuss or add information to a bookplate, and a 'Contribute an Item' tab they could use to upload bookplates of their own. While time constraints prevented the curating of any online exhibitions, a tab for this feature was left on the site to indicate the possibility of this further enhancement of the collection.

Altogether, it took three months from commencement of the digitizing of images for the Ex Libris website to be sufficiently completed and populated to be launched online. The fact that this was able to be done by a single person without technical skills counts as one of this project's research findings, as it demonstrates the practical feasibility of Archives 2.0 for smaller community repositories. A URL address for the Ex Libris site and a screen-grab of the home page are available in the Apendix 1.

\subsection{Second Stage: Research Interviews.}

Nine interviews of between 35 and 75 minutes in length were conducted over a three week period. Of those interviewed, five can be classed as practitioners, 
in the sense that they work professionally for institutions hosting cultural heritage collections. Of these, four are employed by large national institutions, including one academic library. While only one of the five strongly identified himself as an archivist, all had some responsibility for maintaining cultural heritage collections. Three of the other interviewees worked professionally as academics in the area of Information Studies. All had research interests connected in some way with Web 2.0. One had a background as an archivist, while another was an historian of print culture, making her highly familiar with the bibliophile community to whom the Ex Libris site was aimed. The final interviewee was an antiquarian bookseller and the only representative of the original target group of users outside the professional and academic sphere. He provided valuable insight into how the Ex Libris site might be received and used by bookplate enthusiasts. However, his lack of familiarity with Web 2.0 and archival practices meant that his contributions were marginal to the professional issues discussed by other interviewees.

A summary and discussion of the major topics discussed in these interviews is provided in the following section.

\section{Research Interviews Data and Analysis}

\subsection{Prior Awareness of Archives 2.0}

All interviewees were asked to describe their level of prior awareness of either the specific term 'Archives 2.0', or else the general idea of using Web 2.0 interactive tools within online digital heritage collections. Most admitted to never having come across the term 'Archives 2.0' before, although all but one (the antiquarian bookseller) felt immediately able to grasp what it referred to. This was because they were already familiar with the idea of Web 2.0, and related concepts such as Library 2.0.

I certainly hadn't heard the term 'Archives 2.0' before I [was approached for this interview] but I kind of related to it immediately from the library side of things, from that Library 2.0 thing, and thought - okay, so the archivists are doing it too!

Interviewees tended to understand the concept primarily in terms of a specific technology, rather than as part of a wider user-centric philosophy of archival practice. Indeed, one interviewee disliked the '2.0' tag specifically because she saw it as implying 'technological determinism' - the assumption that new technologies can, in and of themselves, bring about required change: 'When I first heard someone say 'Library 2.0' I was just kind of like - puh-leeze.' For her, the phrase was symptomatic of an underlying insecurity among librarians over 'their validity and their place in the Information Society'. This interviewee had not connected Archives 2.0 with the more general idea of a 
user-centric, democratizing approach to archives until it was explained that this was how many of its advocates understood it.

Y'know when you talk about Archives 2.0 as a much bigger philosophy than just that sort of interactivity and platform which you usually associate with Web 2.0, it makes perfect sense, but in terms of the sense of the terminology that's used [that doesn't come across].

Only three participants (one a practitioner, the other two academics) seemed well acquainted with the phrase Archives 2.0 and the professional and academic discussions concerning it. Of these, only the academics identified with the philosophical position it espouses. While several of the interviewees had some experience of using sites of this kind, none had ever used Web 2.0 applications to post comments or upload items.

\subsection{Assessment of Current Situation}

The overall impression conveyed by interviewees was that while there exists considerable enthusiasm for the Web 2.0 concept within the New Zealand cultural heritage sector (particularly for enabling user comments on online collections), there was little systematic momentum to implement it. This situation was characterized by one interviewee as 'almost like a de-coupling' between institutional ideas and institutional practice:

Web 2.0, Library 2.0, Archives 2.0, New Museology, that sort of thing - it's like this is what we want theoretically. But operationally - phht! We're still way back here.

Reference was also made to failed past attempts at Web 2.0 implementation, particularly a major online collection which still has a comments feature attached to each item. An accompanying notice reads: 'This function coming soon.' But as a practitioner associated with the project explained, this was never going to happen. The project had been abandoned 'because the whole thing proved too difficult. We lost some funding, we lost the experts, we were a bit ambitious with it, and so it's been a failed experiment.' In the view of one interviewee this was 'just what you don't do - start something and not see it through.' Another of those spoken to, however, saw this as evidence of institutions moving in the right direction:

When you've got momentum you've got to be prepared to fall over. And it's not something libraries and archives do very well, is fail well. We tend to fail badly and not learn from the experience, or decide that that means that's a bad direction to go in.

This interviewee had the most positive perspective on current developments, partly because she was the only person spoken to who was actively involved in 
implementing a Web 2.0 strategy for a major institution. (Unfortunately, because she was the last person interviewed, her comments could not be referred to other participants for discussion.) Recently appointed to a new position at her institution with a specific brief to facilitate online access to digitized material, she believed there were two basic models for Web 2.0 implementation. The first, which she referred to as 'the money option', was to 'build it yourself. You really invest in your main search and discovery experience, and you bolt things onto that.' However, due partly to the expense involved, her own institution had gone for the alternative option of 'using other people's stuff', ie, third party providers of social media sites: 'You use FlickR, you use whatever you can get your hands on, where the people are, and you go there.'

Another practitioner spoken to earlier had been deeply distrustful of third party sites on the grounds that they involved becoming dependant on an external organization with its own commercial interests ('They've been known to rather arbitrarily change the rules on people.') In contrast, the interviewee who was most positive about current developments was less troubled by these concerns, while still emphasizing the need to choose providers carefully and have an exit plan. She also conceded that using third party sites entailed some loss of control over the interactive environment, but saw these disadvantages as being outweighed by heavier user traffic and the connection to other institutions that would allow her institution 'to participate globally in a way that we can't do out of our own resources.' She characterized the strategy her institution was undertaking as one of 'turning browsers into users', ie using items posted on social media sites to lure researchers into engaging with the home system. The latter was currently undergoing a substantial re-vamp that would provide it with limited capacity for inter-activity, although the precise nature of this was yet to be determined.

More generally, interviewees were asked for their assessment of the current situation with regard to digitization for online access - a necessary precursor to Web 2.0 implementation. The overwhelming consensus was that there was 'quite a strong mandate' for digitization of this sort and that it was increasingly seen as 'a priority'. At the same time, many felt that it was not being systematically done to the extent that it could be. For example, one noted the 'huge disparity' between what Archives New Zealand and the National Archives of Australia are 'making freely available in digital'. Once again, the practitioner with the most direct Web 2.0 involvement offered the most positive assessment of the current situation. She regarded her own organization as having reached 'a tipping point,' where it had acquired sufficient 'critical mass' for its digitized resources to be 'managed in bulk.' She saw this as the consequence of 'highly systematized processes' developed from many years of experimentation, during which 'we had tried this and tried that'. Others also referred to what they saw as an earlier haphazard phase of 'mass digitization' which was seen to have dried up due to lack of funding. One 
interviewee characterized the current strategy as 'sort of going in more deeply with fewer records.'

\subsection{Impediments to Digitization and Web 2.0}

Lack of resources was by far the most often identified impediment to the development of online digital collections with Web 2.0 functionality. Many interviewees were keen to point out that while an open source Web 2.0 platform might superficially appear a cheap, hands-off means of providing access to a collection, it actually entails considerable hidden costs. The amount of staff time required to provide adequate metadata or to monitor user input was a constant refrain from practitioners. It was generally felt that within the current climate of economic retrenchment, Archives 2.0 style initiatives would, for the time being, take a back foot to other more pressing needs.

I think the big stumbling block, really, is time and money. Y'know, things have to be stacked in the queue, there are priorities and there are some projects that get the nod and some that don't.

As an example, one interviewee mentioned that he was personally keen to host a collaborative online digital project that would bring together on a single website the papers of a prominent historical figure, currently dispersed throughout the country. Unfortunately,

We just haven't got the resources to do it, because we can barely keep up with our own stuff. And so something like that would be a wonderful thing to lead but increasingly in this environment, where costs are getting cut, I don't think you could. But I think in a more expansive financial environment we were moving to a situation where we might've taken the lead ... But it's not going to happen now.

The higher priority identified in this case was the need to 'update our clunky old database'. An even more prosaic instance of the type of choices practitioners feel forced to make was provided by another interviewee:

When I was doing my research I went to a particular library system and I said to them: 'Have you thought about setting up a federated interface across your museum, libraries and archives collection?' And she said 'Of course we have. Of course we would love to. Of course we know that it's user-centric, we know that it's a great platform' and all that sort of thing. 'But,' she said. 'we need new chairs.'

Y'know, it's all about the prioritization of resources. And to me that just really emphasized the whole underlying point about [online digital initiatives of this kind]. Yes we know it's sexy, yes we've see the potential, we're not idiots. It's 
not that it's just not happening, it's not happening for a reason, because other things such as chairs (which are quite important in a library!) take priority.

All interviewees considered lack of resources to be a real and significant issue. At the same time, some also felt this was sometimes used as an excuse to avoid innovation. One interviewee saw the 'enormous upheavals' recently inflicted on the cultural heritage sector as having created a widespread resistance to change, even of the more creative kind. Within this context, invoking resource constraints and higher priorities could serve as 'red herrings':

If there's not the institutional drive then you won't get [the results]. You put your money where your mouth is. And if you don't have that kind of vision - or you just talk the talk, without walking the walk - then I think you'll make any excuse to avoid change.

These kinds of factors, related to organizational culture and professional mindset, were identified by a number of other interviewees as impediments to the adoption of Archives 2.0. For example, practitioners working in large public sector organisations often made reference to the inhibiting effect of bureaucratic procedures: 'Whenever you want to do anything you've got to go through all this sort of [makes exasperated noise] to finally get approval.' Others saw traditional attitudes within the archival profession as a significant barrier to be overcome before users are given freer access to online collections. 'I feel that there's a lot of conservatism amongst practitioners, [. . .] there's still a lot of gate-keeping, a lot of control.' Another felt that while some archival institutions had adjusted to the fact that research had moved into a 'a composite multimedia world. . . [others] used to a certain brand of researcher, and a certain type of research setting, are more difficult to shift.' The interviewee who most strongly identified himself as an archivist felt the fact that his profession was 'a fairly aging workforce' was an important factor in why members were slow to take up new technologies like Web 2.0. However, he saw this as having more to do with lack of awareness than active resistance, which he saw as beginning to change. Other interviewees cited 'that quest for perfection' that both archivists and librarians could be 'quite big on' as slowing down the process of providing metadata or curating online exhibitions.

\subsection{Institutional Collaboration}

Most interviewees felt that a variety of institutional collaborations were increasingly taking place within the New Zealand cultural heritage sector. In terms of digital collaborations, the combined online database Matapihi was cited as an example, while efforts to co-ordinate digitization projects were also mentioned. At the same time, it was generally recognized that little had been done to develop more thematically-focused virtual collections, built out of digital resources sourced from multiple repositories. The reference point for 
interviewees was the experimental Ex Libris website being used to host bookplates contributed by different institutions from throughout the country.

Interviewees were broadly welcoming of this possibility: 'I' $m$ all for that'; 'I think it's a fantastic idea'; 'The application for that kind of thing is just huge.' They saw collaborative sites of this kind as an example of 'the powerful things that digitisation can do' and, in particular, as a means of satisfying users' desires for a 'one-stop shop.' A couple of interviewees mentioned their own long-standing interest in the idea of creating virtual archival collections. Yet while collaborations of this kind had been the subject of discussions between institutions, there was no sense of any actual project being imminent. As another interviewee put it:

Well, that kind of collaboration is talked about a lot. Convergence is what everyone talks about - but do they do it? I'm not seeing much evidence of that.

When asked if their own institution would contribute bookplates to the experimental Ex Libris website if it were hosted on another institution's server, most practitioners believed there would be openness to this idea but were unsure whether it would actually occur. In contrast, the bookseller interviewed felt confident that private collectors would welcome the opportunity to contribute items. One practitioner suggested the type of decision-making that would be involved for her institution:

Well, I think that we'd assess it. Are people using it? Is it worth our time? Is there a community of use there already? Then we would ask: How do we want to be identified on the site? What does your site allow people to do with our material? Can we place our own terms and conditions?

Other practitioners felt that 'people's sense of strong ownerships of their collections' was likely get in the way of any institutional collaboration:

[T]rying to get some institutions to cooperate can be quite a battle. Especially if [the collaborative website is] set up by one institution, and these other institutions feel like, that's fine, but if they collaborate this other person is getting all the [kudos]. . . My experience [is] that you would probably have to have about ten years of negotiation about ownership of the material or where it was going to be housed. That's the impediment that I see.

Both this interviewee and another felt that institutions would be more likely to be involved in collaborative projects if they were only required to place metadata and hyper-links to their items on another host site, allowing the items to still be viewed within the confines of the institution's own 'brand'. 
We're very uncomfortable about [items from our collection] being housed on a server that's not where our stuff resides. It's a bit of that sense of ownership, and a bit of that sense of responsibility for the material.

As one of the academics observed, it was at 'that human level' of resourcing and ownership issues that the desire for collaboration 'gets tetchy and falls apart.' Similarly, another saw 'all these institutional barriers being thrown up' as the reason why '[digital] media convergence' was not occurring.. Otherwise, she felt, this was "a no-brainer."

\subsection{Re-use}

Facilitating the re-use of archival materials was a central issue for some of the practitioners interviewed. The practitioner most closely involved with Web 2.0 thought that within her professional circle Web 2.0 was subsumed by the 'much larger idea of being able to re-use and release material.' Accordingly, she saw her institution's initiatives in this area as primarily about the wish 'to release material for re-use easily and without a lot of administration on our part.' Another practitioner identified 'that whole re-use, re-purposing kind of thing' as one of the principle benefits offered by Web 2.0, and one of her criticisms of the Ex Libris site was that it was light on these features.

There were also signs that the move towards promoting re-use was creating anxiety within the profession. The practitioner who most identified as an archivist confessed that "the word "mash-up" still brings a bit of a shudder to me.' He characterized his position as 'this sort of conservative approach that the things we have should stay as the things they are.' He also admitted to feeling 'a certain proprietary concern' over the items in his charge, and believed that those made available for re-use should not only be fully attributed to their source, but also kept in a manner which, as much as possible, respected their original form. He disapproved of Digital New Zealand's Mix and Match competition, which had encouraged people to experiment with data re-combinations involving cultural heritage material:

I have a problem with people taking the heads off one image and [putting them on another] - y'know making funky posters out of [our institution's] images. Others say that it doesn't really matter but I haven't quite got there yet.

This interviewee did emphasise that he fully supported moves to allow the public to download high definition images without charge from his institution's online collections. This was despite the fact that there had been 'some conservative reaction' against this from other staff worried that it would make material 'too freely available'. His own position was that it was good to make items more freely available, so long as this was 'under [the] sort of conditions that say you can only do this with it, or you can't do that with it.' 
His belief in the need for restrictions to govern how an archival item might be re-used was firmly rejected by a number of the other interviewees. As one put it:

What - they're worried that people might use it wrong? I just don't buy into that. I think, y'know, if you start going down that track you're heading towards hegemony or something. Archivists have got a historic mindset, I think, about people understanding things 'correctly'. Well, y'know, what's the issue?

Similarly, one of the practitioners spoken to saw restrictions of this kind as 'limiting the role of valuable information.' She strongly supported 'encouraging re-use. . . I don't have the same hang-ups that other people have about that.' Another interviewee expressed surprise at the idea that archivists might think they could possibly control the use of material released in this way. 'If someone wants to pull pieces out of [your collection] and go and do whatever they want with it, you do have no control over that. So I think it's kind of a moot point.' She considered mash-ups valuable tools because she liked 'the ability to manipulate layers of information, of genres, formats ... That, to me, is the key benefit of a digital platform.'

However, the practitioner most closely involved in providing online digital access was sympathetic towards anxieties about re-use. She perceived her own role as finding the right balance between making it easier for the public to gain access to and creatively engage with images held within her institution's collections, and accommodating curators' concerns that these not be used inappropriately. Since the only images her institution had chosen to make available were ones without copyright or donor restrictions attached, she saw its attention as having become focused instead upon managing what she described as 'intangibles': ' $Y$ 'know, respect of the item, of the subjects of the item, cultural sensitivities. . .' As a 'general all-purpose example' of the kind of re-use her institution was striving to preclude, she made reference to an online 'joke' photograph of Governor George Grey: when viewers ran their cursor across this image, his pants fell down. More broadly, she spoke of the wish to prevent anything that could be seen as 'out of the spirit of the time' and context in which an image was produced. This included any re-presentation of the image that might involve cropping it or overlaying it with another image.

The mechanism for conveying these restrictions was the 'Terms and Conditions' which users must agree to before downloading items. This interviewee was well aware that 'there are limitations as to what you can do with terms and conditions. Y'know, once you've let it out, you've let it out - the horse has bolted.' She also frankly admitted that there was a certain 'impossibility' to the task her institution was setting itself, while insisting that 'the intent is genuine.' That intent was to foster 'respect' and 'rais[e] awareness' of the value and dignity of the historical resources her institution held, and the 
people whose past lives they recorded. She also saw measures to influence how items digitally released to the public were subsequently re-used, as necessary to prevent any counter-reaction. 'Things could go very negatively in the other direction. We might suddenly start not digitizing lots of images.' She felt that 'people are torn in our profession' between 'want[ing] to make things available - that's what we're here for' and protecting the dignity of their resources something she saw as becoming increasingly difficult in a digital age.

\subsection{User Comments and Contributions}

The ability of users of online digital collections to comment on and add descriptive information to items, as well as to contribute items of their own, can be considered defining practices of Archives 2.0. In principle at least, this kind of functionality was welcomed by all those interviewed. Summarizing the potential benefits of enabling user input, one practitioner noted that it would allow 'you to build a community of knowledge' around an online collection, to 'enhance the information value around particular objects', and to 'create linkages between things that you haven't considered which other people might know about.' Another practitioner observed that while her institution did not have a full-fledged user input mechanism in place, it was 'definitely moving in that direction.' She was enthusiastic about 'the whole idea of encouraging people to contribute to descriptive practice, to correct stuff'; as well as add their own search terms 'which might actually be more instinctive or intuitive for a user'. Other interviewees commented on the potential of allowing users to add their own items to an online repository for growing a collection and uncovering material that might otherwise remain unknown.

The main proviso stipulated by most interviewees was the need for user input to be clearly identified. 'It has to be - and I suppose it will be - obviously kept apart from the official bit. Otherwise you end up in a real muddle.' Another interviewee regarded this kind of demarcation as integral to the whole Archives 2.0 concept:

I believe it's a theme in Archives 2.0 that if you have your user comments and you have your user contributed material, you make it very clear what's that, and what's yours. So you have them alongside but, y'know, you [distinguish them]. . . Interlinked but still quite separate.

Two of the academics expressed interest in the possibilities presented by a more 'radical' wiki style set-up, in which any distinction between user and staff contributions are blurred. However, both considered that its workability would depend on the specific goals and circumstances of the project.

The other major concern held by most interviewees was the requirement for user input to be regularly monitored. This was seen as necessary for a number 
of reasons, including having to respond to queries and to keep in check 'derogatory comments, and things that aren't helpful or ... misleading.' One interviewee observed that even when user input did not have to be directly mediated, 'the expert on the back-of-house side of things [will still have] to engage with the whole process in order to make sure that it doesn't get too random. . . And that will cause work.' The staff resources needed to oversee user input was a prominent theme in interviews and was identified as a major barrier to Web 2.0 implementation. One practitioner made direct reference to what she saw as the large amounts of work involved in supervising the user comments and user contributions features on the prototype Ex Libris site:

Yeah, I was thinking if I had been able to do something like this I would be the only person who could monitor it. I don't have staff - and I mean I couldn't do it. Just couldn't do it; just wouldn't have the time. And it would have to be, y'know, they'd have to employ someone part-time or however long it took to do it and there's no way at the moment that there's any money. So, yeah, I see that as quite a big problem.

In contrast, another interviewee cautioned against practitioners getting too 'hung up on' the idea of Web 2.0 taking 'too much time' to monitor. 'I think there is a need for some moderation and work but I'm just saying: let's not make a mountain out of a mole hole.' She was one of several interviewees who suggested that institutions should place more trust in users to alert them to any contentious content.

\subsection{Crowdsourcing Metadata}

With regard to user input, what interviewees were most interested in was its potential for adding to or correcting metadata. Web 2.0 applications were regarded as a crowdsourcing mechanism for leveraging the knowledge of archival users and using this to enhance or complete a collection's records.

In the opinion of one interviewee this was 'definitely the way of the future' for archival institutions, since they 'simply haven't got the resources to make archives all that accessible' on their own. The information they currently provided online about their collections was generally restricted to 'high-level descriptions, often just accession records,' limiting findability and use. At the same time, researchers who were actually using these collections often possessed in-depth knowledge about aspects of it. As this interviewee lamented, 'that stuff is just lost. It's lost.' Her own experience as a researcher was that within a Web 1.0 environment, those wishing to add or correct something in an online finding aid were often discouraged.

[T] here are lots of barriers to getting that information there as metadata. You have to email someone, and that someone has to be receptive to what could come across as a criticism of their work. .. Or else, y'know, these people are 
nearly always very busy [so they may never get around to making the changes. This] becomes a put off. . . If [, however,] you can add something, a comment yourself, and if you know that comment's going to stay there and it's going to be searchable, then you feel inclined to make the effort.

While all those interviewed thought it helpful for users to be able to append information in this way, most also believed this required close monitoring. This was not just to address misinformation, but also to acknowledge and make practical use of contributors' efforts. The general view was that worthwhile information needed at some stage to be verified for accuracy and incorporated back into the archives' official metadata.

One of the reasons for moderation is that at some point you might want to actually 'repatriate' some of that data in as authorized data, validate it and check it, and I think that's really the most useful role for librarians or archivists in terms of [monitoring user input]. . .I think that's a really good use of people's time.

Other interviewees emphasized the need to show contributors respect. For one, the issue was less about institutions having to monitor user comments, than about deciding what they were going to do with them: 'Is it going to respect the people who are the purveyors of the comments and revise the main text? Or are they just going to see it as chatter on the side?' Another interviewee echoed this sentiment, while also worrying about how timeconsuming verifying these contributions might prove:

The concern for our curators and arrangement and description staff is that people will feed back a lot of information. They'll say this is my greatgrandfather, and they did this and they did that. And we want to take advantage of that [information] and bring it back into our home systems. But of course there's work [involved] in order to at least moderately assess the authority of that person to say that thing. . . [On the one hand,] we don't want to have to do a lot of original research to verify that [information]. But on the other hand, we want to get something out of the experience for us as an institution, and that kind of information is really precious.

\subsection{Authority Control}

The perceived need to diligently monitor and validate user input is closely related to wider issues of authority control. Having traditionally prided themselves on the accuracy and authenticity of their information, many archivists are concerned that Web 2.0 features might cause large amounts of unreliable data to be placed on their websites. This could undermine the overall credibility of a collection and lead to a situation in which researchers no longer trust these resources. This position was well summarized by an 
academic who acknowledged her own disinclination to consult sites with large amounts of user-contributed information. This was because she had

this authority thing about information. . . in that I want to be sure that the information I'm looking at is authoritative. . . [However,] if I knew that the material that's been uploaded [by users] was regulated, then l'd be more likely to use it. But that would also depend on who was regulating the site. I mean if it was the local archivist and they'd developed this site and you could contribute and upload information and material - and I knew that that site, that material, was being regulated by that archivist - then l'd be much more willing to use the information there.

There's [a certain level of] trust [required] and I think that, with the archival profession, there's an element of trust and respect for their skills and that level of authority that they have over their materials, and the way that they know their collections. Whereas, y'know, if it was just Joe Bloggs down the road doing it, regardless of the professionalism of the site and the materials they used and the information on there - to me it still doesn't have that same stamp of authority.

A couple of the other interviewees took issue with this attitude. 'I don't buy into this whole 'We've got to protect our authority” thing,' observed one, 'because, frankly . . . I find so many errors in archives metadata. It isn't authoritative.' The other was equally dismissive of 'this whole fixation on authority. Authority is in the eye of the beholder, of the person in control.' Both made reference to postmodernist perspectives to suggest that many archivists remained stuck in an outdated positivist mindset. One felt there was

this sort of unrealistic idea about evidence in the archives community. We still equate it with the notion of proof, of really hard evidence. But evidence is not like that, sometimes it's highly subjective, highly interpretive.

The other posed the question:

What are facts anyway? They're contextually-based - and even more so within an institutional setting. You can have the same object, described ten different ways, used twenty different ways, and people have different informational needs and different information perceptions about that same thing. So who's to say your description is any better or more authoritative than mine?

Both identified a problem with archival institutions thinking 'they [had] too much at stake in providing the ultimate information. They think they're the guardians of that information in toto.' They saw a need for archivists to 'get off their pedestals,' 'loosen their grip,' and allow 'multiple perspectives' to emerge. Researchers should be trusted to make their own judgements about a contribution's worth, regardless of whether it has the imprimatur of institutional authority. With reference to the Ex Libris site, one interviewee 
noted that in her experience as a print historian, some of the most valuable information came from private book collectors. This concurred with the views of the antiquarian bookseller, who confessed to never having consulted an institutional cultural heritage website. Instead, he relied for his research on community-regulated websites maintained by collectors and bibliophiles.

\subsection{Improving User Input Management}

The major criticism most often made about the prototype Ex Libris site was that its 'Comments' feature was too basic to allow information from users to be effectively solicited and organized. It was pointed out that the word Comments on its own was too vague an instruction to encourage people to add or correct metadata, rather than just post feedback of the 'this is awesome' kind. It was suggested that a simple 'Do you have any information to add to this?' would help to direct contributions better, and avoid mundane 'clutter'.

Some interviewees suggested going further. Rather than a single space for adding content to an item, they wished to see user input being directly attached to specific metadata fields. One of the practitioners happened to know important information that was missing from the metadata for one of the bookplates on the Ex Libris site, but was deterred from adding this by the unstructured character of the 'Comments' feature:

It was frustrating for me that the only place you could contribute was in the "Comments" thing, whereas you actually want to be quite specific. . . [I found it] kind of a disincentive to [have] to write in the "Comments" that this [information] was relating to that field, whereas I expected to link directly to where I wanted to add value.

She felt that being able to directly add content in this way would convey to users a sense that their input was 'really valued.' It would also save on staff time:

Because the other thing is that [having a single space for "Comments"] means you've got work to do, you've got to read the comments and figure out what you're going to do with [them]. Whereas if [user input is] attached to a field even if it's a local version of an authorized field - then it's going to go exactly where it needs to go and you don't need to intervene. Because frankly we don't have enough time $-y$ 'know we could be off solving copyright problems or something.

This view was echoed by others. One interviewee said that she would 'love to see more encouragement for user-contributions to be in the form of structured data.' This would not only render the data 'more useable' by allowing it to be directly placed where it was relevant, but would also provide contributors with 'a prompt. . . and an incentive (it's a helluva lot quicker to add a name to a 
field than it is to write a comment).' This interviewee was also keen on the idea of archival websites identifying the provenance of their metadata. As a researcher, she was annoyed that online collections generally neglect to credit the source of their information. 'I am constantly having to email people and say, y'know, where did this date come from? How do you know?' Often they were unsure, which this interviewee saw as indicative of an 'authority mindset: we say it, you believe it.' If both official and user-contributed metadata were managed as records - meaning that information included the context of its creation - researchers would be empowered to make their own assessments of worth. Provenance information of this kind could be kept 'behind' the item page itself, so that it could be viewed only by those wishing to access it.

A couple of other interviewees made similar suggestions about ways Archives 2.0 could better exploit the flexibility of electronic media by providing users with more options about the kinds of information they accessed. One argued that there was a need to get away from 'this card catalogue mentality where we think it all has to be packaged up on one card or screen.' Instead, online collections should be letting 'people come in and select the angle [. . .] that's of interest to them.' Another interviewee spoke in terms of a vertical model where information would be stratified according to the degree it had been validated. A 'filtration system' would allow some contributions over time to drop down to the most authorized level while still retaining a multiplicity of views:

It shouldn't be either/or - y'know? It should be layered. It's like maintaining the archival integrity of the collection, series, whatever, but yet still enabling that sort of openness and that democratized access as another layer on the top.

\subsection{Crowdsourcing Correction and Transcription}

Many interviewees regarded crowdsourcing the labour of online volunteers to correct Optical Character Recognition (OCR) text, or to transcribe handwritten manuscripts, as a potentially useful application of Archives 2.0. Several made positive reference to the popular newspaper correction service found on Trove, the website of the National Library of Australia. This enables online researchers to correct the errors they inevitably come across in the OCR text accompanying digitized newspaper articles, facilitating ease of reading and accurate searching. Most interviewees saw this crowdsourcing technique as a practical tool for enhancing the quality of the resources archival institutions provided online, while minimizing workload on their own staff. It was also seen as a worthwhile way of promoting a collection and developing a community of interest around it. 
Using the crowdsourcing model, [Trove] are bringing communities online which is everybody from genealogists, to just interested newspaper readers, to full-blown researchers who, as they're using those texts, are making the changes as they go. So a much more interactive environment [than what we currently find in New Zealand].

Another interviewee was interested in the way Trove encouraged participation by 'game-ifying' its newspaper correction service. Not only are text correctors accorded recognition by being able to identify themselves, but a 'Leader Board' ranks the most prolific contributors - introducing an element of friendly competition. This interviewee saw 'game-ifying' initiatives as a useful way of building up user communities around Web 2.0 sites.

A related form of crowdsourcing that is gaining traction overseas is 'collaborative transcription.' This involves large numbers of online volunteers giving up small amounts of their time to transcribe handwritten manuscripts a task that otherwise entails a major investment of labour by archival staff. A couple of the practitioners interviewed had never come across this concept before and expressed some wariness about it:

No, I have no experience of that. But how would you know who got it right? You would almost need an editor - and that could be quite a bit of work. . .

Another made the point that great care would need to be exercised over what documents you placed online because of the ease with which sensitive passages could be overlooked when dealing with handwritten manuscripts. Other interviewees, however, expressed great enthusiasm for this idea, even bringing it up in advance of being asked about it:

I think those transcription things have got brilliant potential. Look, they've got potential for both opening up the content, but also they're just amazing marketing tools.

This interviewee felt that diaries, in particular, could prove attractive to usersas-transcribers, drawing them into connecting with and caring about a collection: "I mean so much of this stuff is better than novels - people will get hooked in!' Another interviewee was also keen on the idea of collaborative transcription and of using it to engage users with diary collections. Currently, he was encouraging supporters of his institution to participate in a more traditional fashion by transcribing diary entries in a reading room. This kind of established practice was seen by another interviewee as a useful hook for persuading institutions to develop policy in this regard - as collaborative transcription could be presented as an extension of the sort of volunteer help that had gone on in the past ('In lots of libraries that's the hard bit: getting the library to agree on policy!'). 


\subsection{Response to Ex Libris Website}

Interviewees provided plenty of constructive criticism and suggestions for improvement of the Ex Libris site. Some malfunctioning features that had, embarrassingly, been overlooked were reported and basic errors pointed out. One interviewee noted that the ratings feature, which enables users to rate an item between 1 and 5, failed not only to explain the criteria for doing so, but also to indicate which number counted as high. Another expressed her disappointment that only five items could be viewed when choosing to examine bookplates by collection. This was not in fact the case, but it drew attention to the fact that the instruction for viewing more bookplates had been made too small and was poorly placed.

Overall, the general response to the site was positive, although levels of enthusiasm varied. For practitioners from larger institutions for whom the practical value of implementing an Omeka platform themselves was limited, other Web 2.0 options were more likely to engage their professional interests. Not surprisingly, the most enthusiastic reaction to the Ex Libris site came from the two interviewees most directly engaged with its subject matter: the antiquarian bookseller and the scholar of print culture. Both appreciated having rich descriptive content attached to items, and believed there was a definite audience for such a site. The book scholar saw it as having 'a lot of potential for connecting ... with the wider bibliophilic community' and developing 'a community of interest' around bookplates. The bookseller felt there was ' $a$ great unanswered interest in bookplates' and that by addressing that need, an interactive online collection like the Ex Libris site 'adds a pulse to it, gives life to our bookplate legacy.'

\section{Conclusion and Main Findings}

A range of interviewees, with significant differences of interest, professional experience, and knowledge of Archives 2.0, contributed to this research. While there were notable disparities in the views expressed, the overall impression was less of entrenched polarities than of considerable space for consensus. For example, even those who identified most strongly with a conservative position on restricting the re-use of archival resources, were keen on the possibilities they saw offered by Web 2.0. Similarly, those who were most enthusiastic about Web 2.0's potential for transforming the archival environment, also wished to ensure respect for provenance and the dignity of the historical record.

The project's modest scope places obvious limits on the generalizability of its claims. Its sample was small, and neither random nor broadly indicative of those who can be classed as potential users or implementers of a New Zealand Archives 2.0 website. Nevertheless, the rich and nuanced data that the 
interviewees provided about their perception of the relevant issues offers worthwhile insights into current attitudes. The major findings can be summarized as follows:

- There does not appear to be much awareness at present of the term 'Archives 2.0' amongst practitioners of cultural heritage collections in New Zealand. Neither do there appear signs of this concept emerging as a rallying point for 'democratizing' archives in the way in which it is often seen overseas. There is, however, a widespread awareness of Web 2.0 interactive tools and the possibilities these represent for facilitating user input into online digital collections.

- The general perception is that there exists considerable enthusiasm within the cultural heritage sector for the use of Web 2.0 interactive tools. The general perception is also, however, that there is not a great deal happening on that front at the moment. To some degree that perception is contradicted by evidence of a significant Web 2.0 initiative presently being undertaken by a major cultural heritage institution. That initiative is built around a strategy of using third party providers.

- There is a strong view that resource constraints represent the major impediment to implementing Web 2.0 features on archival websites. There is also a strong view that the current economic climate is preventing more initiatives of that kind. Aspects of organizational culture and a 'traditional' mindset within the archival profession are also seen by some as impediments in this regard.

- There is a perception of a general wish for more institutional collaboration within the cultural heritage sector. However institutions' protectiveness of their own interests and procedures is seen to still present a barrier.

- There is a move towards releasing more digital resources online and facilitating their re-use. At the same time, concerns amongst some practitioners about these resources being used inappropriately is leading to efforts to impose terms and conditions.

- There is a great deal of interest in the idea of using Web 2.0 tools to leverage user knowledge about a collection and enhance its metadata. However, the felt need to monitor and validate this information in order to maintain authority control is seen by many as likely to place a major strain on resources. The idea of crowdsourcing online users to undertake tasks like transcription is likewise seen to have potential but similar reservations apply. 
- Generic Web 2.0 applications are seen to have considerable room for improvement. In particular there is a wish to see the enabling of user input as structured metadata, rather than in the form of a general comments field.

- The numerous practical suggestions for improvements to the experimental Ex Libris site demonstrated the value of having user consultation on a prototype when developing an Archives 2.0 collection. 


\section{References}

Benkler, Y. and Nissenbaum, H. (2006). Commons-based peer production and virtue. The Journal of Political Philosophy 14(4), 394-419.

Blouin, F. X. (1999). Archivists, mediation, and constructs of social memory. Archival Issues, 24(2), 101-112. Retrieved from Wilson Web database.

Brothman, B. (2001). The past that archives keep: Memory, history, and the preservation of archival records. Archivaria 51, 48-80.

Cook, T. (1990/91). Viewing the world upside down: Reflections on the theoretical underpinnings of archival public programming. Archivaria 31, 123134.

Cook, T. (2000). Archival science and postmodernism: New formulations for old concepts. Archival Science 1(1), 3-24.

Cook, T. (2001). Fashionable nonsense or professional rebirth: Postmodernism and the practice of archives. Archivaria 51, 14-35.

Cox, R. J. and the University of Pittsburgh archives students. (2007). Machines in the archives: Technology and the coming transformation of archival reference. First Monday 12(11) http://firstmonday.org/htbin/cgiwrap/bin/ojs/index.php/fm/article/view/2029/1894

Daines, J. G. \& Nimer, C. L. (2009). Web 2.0 and Archives. The Interactive Archivist: Case studies in utilizing Web 2.0 to improve the archival experience. http://interactivearchivist.archivists.org/

Dorner, D. G., Liew, C. L. and Yeo, Y. P. (2007). A textured sculpture: The information needs of users of digitized New Zealand cultural heritage resources. Online Information Review 31(2), 166-184.

Duff, W. and Harris, V. (2002). Stories and names: Archival description as narrating records and constructing meanings. Archival Science 2, 263-285.

Ericson, T. L. (1990/1991). Preoccupied with our own gardens: Outreach and archivists. Archivaria 31, 114-122.

Evans, M. (2007). Archives of the people, by the people, for the people. The American Archivist, 70(2), 387-400. 
Finn, A. (2010). 'An attack on professionalism and scholarship'?: Democratising archives and the production of knowledge. Ariadne 62. Accessed at:

http://www.ariadne.ac.uk/issue62/flinn

Freeman. E. T. (1984). In the eye of the beholder: Archives administration from the users point of view. American Archivist 47 (Spring), 111-123.

Goulet, Marlene. (2010) Archives 2.0: The next generation websites for archival holdings. Bachelor of Applied Science Thesis, Haute Ecole de Gestation de Geneva, Information Science Faculty. Accessed at: http://doc.rero.ch/lm.php?url=1000,41,9,20101110095030-VL/TDB_2120.pdf

Grabowski, J. J. (1992). Keepers, users, and funders: Building an awareness of archival value. American Archivist 55(3), 464-472.

Harris, V. (1997). Claiming less, delivering more: A critique of positivist formulations in archives in South Africa. Archivaria, 44, 132-141.

Hedstrom, M. (1998). How do archivists make electronic archives usable and accessible? Archives and Manuscripts 26(1), 6-22.

Huvila, I. (2008). Participatory archive: Towards decentralized curation, radical user orientation, and broader contextualization of records management. Archival Science 8(1), 15-36.

Jenkinson, H. (1980). Selected Writings of Sir Hilary Jenkinson (Gloucester [Eng.]: Allan Sytton).

Jimerson, R. C. (1989). Redefining archival identity: meeting user needs in the Information Society. American Archivist 52(3), 332-340.

Kennedy, M. (2009). Cautionary Tales: Archives 2.0 and the diplomatic historian. Ariadne 61. Accessed at:

http://www.ariadne.ac.uk/issue60/kennedy/

Ketelaar, E. (2003). Being digital in People's Archives. Archives and Manuscripts 31(2), 8-22.

Ketelaar, E. (2008). Archives as spaces of memory. Journal of the Society of Archivists, 29(1), 9-27.

Liew, C. L. (2006). Online cultural heritage exhibitions: a survey of strategic issues. Program 40(4), 372-388.

Light, M. and Hyry, T. (2002). Colophons and annotations: New directions for finding aids. The American Archivist 65(2), 216-230. 
Krause, M. and Yakel, E. (2007). Interaction in virtual archives: The Polar Bear Expedition Digital Collections next generation finding aid. The American Archivist 70(2), 282-314.

Madden, M. and Fox, S. (2006). Riding the waves of 'Web 2.0'. Pew Research Center Publications [online]. Accessed at:

http://pewresearch.org/pubs/71/riding-the-waves-of-web-20

Malbin, S. L. (1997). The reference interview in archival literature. College and Research Libraries 58(1), 69-80.

Miller, P. (2005). Web 2.0: Building the new library. Ariadne 45. Accessed at: http://www.ariadne.ac.uk/issue45/miller

Nesmith, T. (2002). Seeing archives: Postmodernism and the changing intellectual place of archives. The American Archivist 65 (Spring/Summer 2002), 24-41.

Nogueira, M. (2010). Archives in Web 2.0: New opportunities Ariadne 63. Accessed at www.ariadne.ac.uk/issue63/nogueira

Normore, L. (2003). Studying special collections and the Web: an analysis of practice. First Monday: Peer-Reviewed Journal on the Internet 8(10). Accessed at: http://131.193.153.231/www/issues/issue8_10/normore/index.html

Notess, G. R. (2006). The terrible twos: Web 2.0, Library 2.0, and more. Online 30(3), 40-42.

Palmer, J. (2009). Archives 2.0: If we build it will they come? Ariadne 60. Accessed at http://www.ariadne.ac.uk/issue60/palmer/

Palmer, J., Stevenson, J., et al. (2011). Archives Hub Blog [Online blog]. Accessed at: http://archiveshub.ac.uk/blog/

Reason, P. and Bradbury, H. (2008), Handbook of Action Research: Participatory Inquiry and Practice, $2^{\text {nd }}$ ed., Sage Publications, London.

Ridolfo, J., Hart-Davidson, W., and McLeod, M. Balancing stakeholder needs: Archive 2.0 as community centered design. Ariadne 63. Accessed at: http://www.ariadne.ac.uk/issue60/ridolfo-et-al/

Rosenbusch, A. (2001). Are our users being served? A report on online databases. Archives and Manuscripts 29(1), 44-61.

Samouelian, M. (2009). Embracing Web 2.0: Archives and the newest generation of web applications. The American Archivist, 72, 42-71. 
Schaffner, J. (2009). The metadata is the interface: Better description for better discovery of archives and special collections, synthesized from user studies. Report produced by OCLC Research. Accessed at: http://www.oclc.org/programs/publications/reports/2009-06.pdf

Schneiderman, B. and Plaisant, C. (2004). Designing the user Interface: Strategies for Effective Human-Computer Interaction. $4^{\text {th }}$ ed. (Boston: Addison Wesley).

Shilton, K. and Srinivasan, R. (2007). Participatory appraisal and arrangement for multicultural archival collections. Archivaria 63, pp. 87-101.

Somekh, B. (2006), Action Research: A Methodology for Change and Development, Open University Press, Maidenhead.

Stevenson, J. (2008). 'What happens if I click this?': Experiences of the Archives Hub. Ariadne 57

http://www.ariadne.ac.uk/issue60/stevenson/

Tapscott, D. and Williams, A. D. (2007). Wikinomics: How Mass Collaboration Changes Everything (New York: Penguin).

Theimer, K. (2011). ArchivesNext [Online blog]. Accessed at: http://www.archivesnext.com/

Umbach, J. M. 2006. Web 2.0 - the New Commons. Feliciter, 52(5), p.192

Yakel, E. (2000). Thinking inside and outside the boxes: Archival reference services at the turn of the century. Archivaria 49 (Spring), 140-160.

Yakel, E. (2006). Inviting the user into the virtual archives. OCLC Systems \& Services: International digital library perspectives 22(3), 159-163.

Yakel, E., Shaw, S., and Reynolds, P. (2007). Creating the next generation of archival finding aids. D-Lib Magazine 13(5-6). Accessed at:

http://www.dlib.org/dlib/may07/yakel/05yakel.html 


\section{Appendix 1: Ex Libris Prototype Website}

The experimental Archives 2.0 website constructed for this project can be viewed at the following URL: http://exlibris.iceberg5.net/

A screen grab of the home page is presented below.

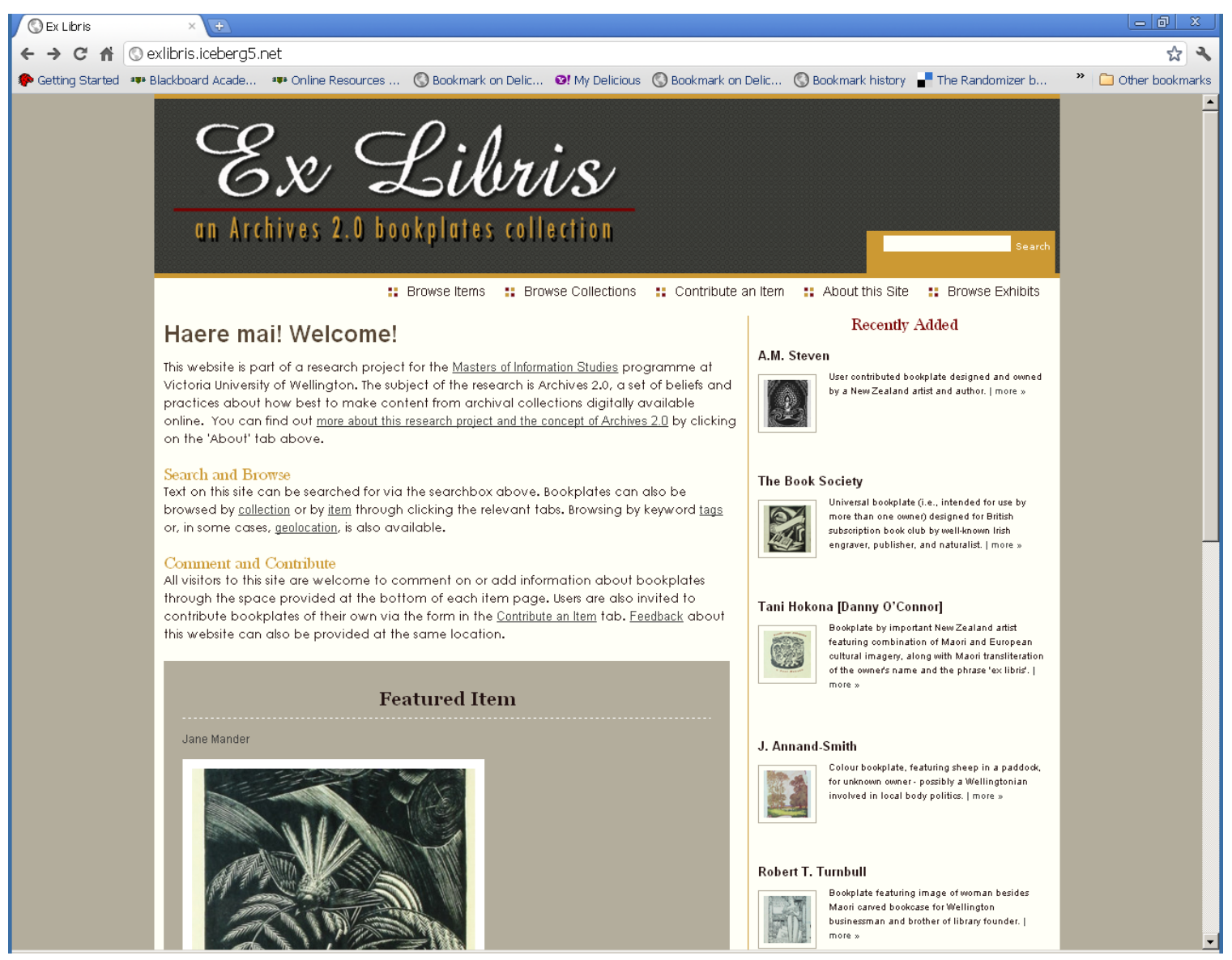




\section{Appendix 2: Participant Information Sheet}

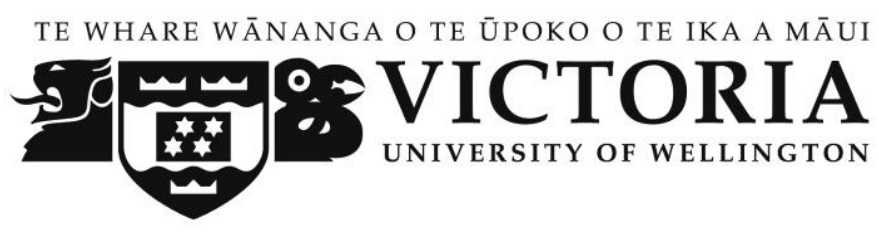

\section{Participant Information Sheet for a Study on Archives 2.0}

Researcher: Reid Perkins: School of Information Management, Victoria University of Wellington.

I am a Masters student in Information Studies at Victoria University of Wellington (VUW). As a requisite part of my degree I am undertaking a research project from which a formal report will be produced. My particular project involves investigating attitudes towards the use of Web 2.0 interactive technology on cultural heritage digital collections websites. VUW ethical approval has been obtained for this project, as is required for all research involving human participants.

As a potential user or implementer of Web 2.0 archival collections you will be asked to view an experimental Web 2.0 website which I have constructed based on the Ex Libris collection of the J. C. Beaglehole Room at the Victoria University of Wellington Library. I will then ask you about your understandings of and responses to this website. This interview will be conducted face-to-face with voice-recording technology if possible; otherwise you may be interviewed by phone. Interviews will not exceed 45 minutes. Your response will form part of the basis for my research project. You will not be personally identified and no person other than myself or my supervisor, Dr. Gillian Oliver, will be able to read or listen to your interview as a whole. Brief quotations may be included in the final written document and research publications, but any quotations will be anonymized through the use of pseudonyms. You can withdraw your consent from the project at any time up to 25 October 2011, when data analysis is scheduled to commence.

A summary of my findings from this research will be emailed to all participants. The final written report will be submitted for marking to the School of Information Management and deposited in the University Library. All interview material will be destroyed 2 years after the conclusion of the project.

If you have any questions or would like to receive further information about the project, please contact me at perkingeor@myvuw.ac.nz, phone (04) 9021130, or my supervisor, Dr. Gillian Oliver, at the School of Information Management at Victoria University, P O Box 600, Wellington, phone (04) 4637437.

Reid Perkins 


\section{Appendix 3: Participant Information Sheet}

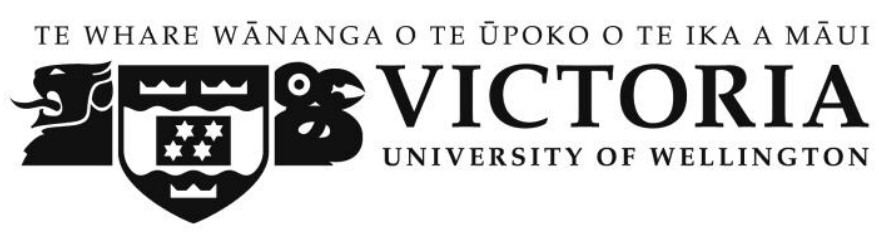

\section{Consent to Participation in Research}

Title of project:

\section{Study of an Experimental Archives 2.0 Bookplates Collection}

I have been given and have understood an explanation of this research project. I have had an opportunity to ask questions and have them answered to my satisfaction. I understand that any information I provide will be kept confidential to the researcher and his supervisor; that the final written report will not use my name or attribute my opinions in any way that will identify me; and that I may withdraw my contributions from this project at any time up until 25 October 2011. I also understand that I will receive an emailed summary of the researcher's findings when these become available and that all records of the interview itself will be destroyed two years after the project's completion.

I agree to take part in this research.

Signed:

Name of Participant: 